Published in final edited form as:

Horm Metab Res. 2009 September ; 41(9): 687-696. doi:10.1055/s-0029-1231025.

\title{
Treatment of Malignant Pheochromocytoma
}

\author{
R. Ajallé ${ }^{1}$, P. F. Plouin ${ }^{2}$, K. Pacak ${ }^{3}$, and H. Lehnert ${ }^{1}$ \\ 1 1st Department of Medicine, University of Lü beck, Lü beck, Germany \\ ${ }^{2}$ Hypertension Unit, European Hospital Georges Pompidou, University of Paris Descartes, Paris, \\ France \\ ${ }^{3}$ Endocrinology Branch, NICHD, NIH, Bethesda, MD, USA
}

\begin{abstract}
Pheochromocytoma (PCC) is a rare disease, mainly sporadic, but also associated with some familial disorders, with a malignancy frequency of approximately $10 \%$. Only the presence of distant metastases, derived from large pleomorphic chromaffin cells, is widely accepted as a criterion of malignancy. Variable symptoms may be caused by production and release of catecholamines. Since there is no curative treatment for malignant PCC and due to its unfavorable prognosis, assuring quality of life is one of the main therapeutic objectives. Besides a long-term medical treatment of symptoms using selective $a-1$ blockers and nonselective, noncompetitive $a$ and / or $\beta$-blockers, debulking surgery is the first treatment step. In case of a sufficient uptake of ${ }^{123}$ I-MIBG treatment with targeted radiation therapy, use of ${ }^{131}$ I-MIBG is an option as an adjuvant therapy, following debulking surgery. Chemotherapy should be applied to patients without positive MIBG-scan, with no response to ${ }^{131}$ I-MIBG or progression after radionuclide treatment, and especially in cases with high proliferation index. The most effective chemotherapy regimen appears to be the CVD-scheme, including cyclophosphamide, vincristine, and dacarbazine. The so-called targeted molecular therapies with treatment combinations of temozolomide and thalidomide, or sunitinib monotherapy, and novel therapeutic somatostatin analogues have shown promising results and should thus encourage clinical trials to improve the prognosis of metastatic PCC. Within this review the current treatment modalities and novel molecular strategies in the management of this disease are discussed and a treatment algorithm is suggested.
\end{abstract}

\section{Keywords}

pheochromocytoma; paraganglioma; adrenal mass

\section{Introduction}

Pheochromocytoma (PCC) is a rare disease with an estimated prevalence of 1:6 500 to 1:2 500 in Western countries. Many cases are discovered incidentally by computed tomography or magnetic resonance imaging of the abdomen. Compared to the fact that PCCs are only discovered in one to six per million people per year, the number of PCCs found in autopsy series compiled from Sidney, Melbourne, and Auckland was much higher, with a prevalence of $0.05 \%$, one PCC per 2301 autopsies, respectively [1,2].

\footnotetext{
(C) Georg Thieme Verlag KG Stuttgart · New York
}

Correspondence Prof. H. Lehnert 1st Medical Department University of Lübeck Ratzeburger Allee 16023538 Lübeck Germany Tel.: +49/451/500 2306 Fax: 49/451/500 3339 Hendrik.Lehnert@uk-sh.de. 
The peak age of occurrence is in the third to fifth decade of life with almost equal distribution among male and female patients, except for familial PCC occurring at an earlier age. The disease is mainly sporadic, but may also be associated with specific familial disorders. In patients with apparently sporadic (nonsyndromic) PCC, up to $24 \%$ presented with germline-mutations being associated with familial disorders [3], that is, multiple endocrine neoplasia type 2 (MEN2), neurofibromatosis type 1 (NF), von Hippel-Lindau syndrome (VHL), and pheochromocytoma-paraganglioma syndrome (PGL 1, 3, and 4) [4].

\section{Definition and Pathogenesis of Malignant PCC}

Approximately $10 \%$ of pheochromocytomas (with a range of 3-50\% according to different studies) are considered to be malignant [5]. There are no reliable histological features allowing a distinction of a benign from a malignant tumor. Characteristics such as local invasion of tissue or blood vessels, tumor size larger than $5 \mathrm{~cm}$, and DNA ploidy suggest malignancy, but do not with certainty distinguish between benign and malignant tumors [1]. The clinical use of a diagnostic score like the Pheochromocytoma of the Adrenal Gland Score (PASS), based on, for example, invasion, diffuse growth, focal or confluent necrosis, high cellularity or tumor cell spindling [5-7] has not been widely established yet. Comparisons with indices of proliferation are lacking.

Efforts are ongoing to identify solid predictors of malignancy, but only the presence of distant metastases, including loco-regional lymphnodes, is widely accepted as a malignant criterion $[8,9]$. A high expression of vascular endothelial growth factor (VEFG), endothelin receptor type A and B, and heat shock protein 90 (HSP90) only represents an indicator of malignancy [10-12]. Nevertheless, these molecular changes play an important role in the area of the new "targeted therapies", which are discussed below.

A malignant transformation is associated with genetic aberrations. Approximately, up to $24 \%$ of pheochromocytomas have a genetic predisposition [3]. Depending on the presence of genetic aberrations, the occurrence of malignant transformation of a PCC is highly variable. In general, malignancy is more frequently found in PGL (ca. 25\%) than in PCC (ca. $7 \%$ ).

There are large differences between the familial syndromes and their risk of malignancy. For instance, only 3-5\% of PCC, related to a MEN2 and a mutation of the RET oncogene, show a malignant transformation. In contrast, patients with PGL4 are found to have nearly 50\% metastatic tumors [13]. This high risk of malignancy in patients with PGL4 is caused by a mutation of the gene encoding succinate dehydrogenase, subunit B ( $S D H B)$. Specifically, SDH is a four-polypeptide complex (SDH A, B, C and D) located in the inner mitochondrial membrane that catalyses the oxidative dehydrogenation of succinate [14].

The malignant PCCs derived from large pleomorphic chromaffin cells can be found in the adrenal gland, but also in the extra-adrenal paragangliomas of the sympathic chain [15].

Metastasis is defined as appearance of chromaffin tissue at non-chromaffin sites distant of the primary tumor and is also accepted as criteria of malignant disease [16].

Metastasis occurs most frequently in lymph nodes, bone (50\%), liver (50\%) and lungs (30\%) and can appear as many as 20 years after initial presentation [17, 18]. Liver involvement may be the result of direct continuous spread of the primary tumor.

Data suggest differences in the malignant potential of adrenal PCC and extra-adrenal tumors, so-called paraganglioma. In contrast to the benign PCC, which in $85 \%$ originates from the adrenal gland, nearly half of malignant PCC occur at extra-adrenal sites [18-21]. 
Extra-adrenal tumors usually have a poorer prognosis than adrenal tumors. On the other hand, the study of Goldstein et al. analyzing 73 patients referred to tertiary care centers, revealed no difference in the metastatic potential or the prognosis of extra-adrenal tumors compared to adrenal tumors [8]. Thus, a correlation between localization of the primary tumor and its potential for metastases can not be assumed.

\section{Clinical Aspects and Diagnosis}

Symptoms of functioning malignant PCC are variable and caused by production and release of catecholamines from the chromaffin cell, which mainly originates from the adrenal gland. There is no significant clinical difference between benign and malignant disease. Patients mostly suffer from paroxysmal hypertension, headache (ca. 60\%), palpitations (ca. 50\%) and sweating (ca. 40\%) [8]. Vice versa the prevalence of PCC is about $0.1 \%$ in patients with hypertension [6]. Other clinical features include dyspnea, nausea, weight loss, visual disturbances, arrhythmias, and mental problems such as severe anxiety. In malignant PCC, occasionally symptoms may develop as a result of the metastatic growth of the tumor [22].

The diagnosis of pheochromocytoma is confirmed by elevated catecholamine metabolites (metanephrines) in plasma and/or raised $24 \mathrm{~h}$ urinary excretion of fractionated metanephrines [9,23]. Free catecholamines in $24 \mathrm{~h}$ urine should be measured when metanephrine analysis is not available. The superiority of plasma metanephrines is well documented through its enhanced sensitivity and specificity [24]. In addition, plasma dopamine can be considered as a marker of tumor burden in malignant PCC/PGL. Dynamic testing with clonidine is rarely necessary to establish the diagnosis, but may be helpful, especially in borderline cases [25].

The acid-soluble protein serum chromogranin $\mathrm{A}(\mathrm{CgA})$ is co-stored and co-released with catecholamines from the adrenal gland and sympathetic neuronal vesicles [26]. Due to its relatively poor specificity (sensitivity $86 \%$ ) $\mathrm{CgA}$ is mostly used to monitor the response to treatment or to indicate relapse of the disease, but not for diagnostic purposes [27].

Following the biochemical diagnosis, the localization of chromaffin-cell tumors is primarily made by imaging techniques including computed tomography (CT), T2-weighted magnetic resonance imaging, and ultrasound. Because of the possibility of distant metastases, the use of ${ }^{123}$ iodine-labeled metaiodobenzylguani-dine ( ${ }^{123}$ I-MIBG) scintigraphy is highly recommended to localize the hypersecretory adrenergic tissue and is established since 1981 [28]. MIBG-scintigraphy is based upon the similarity of metaiodobenzylguanidine with noradrenaline and its high affinity uptake into chromaffin cells. This method has a specificity of nearly $100 \%$, but a sensitivity of only $78 \%$ [28].

In some familial PGLs, malignant PCCs, and extra-adrenal paragangliomas, MIBG was found to have a reduced sensitivity, and many efforts have been made for newer diagnostic tools, especially for positron emission tomography [28]. The comparative study of Takano et al. found a superior sensitivity of $\left[{ }^{18}\right.$ F $]$ fluoro-2-deoxy-d-glucose ( $\left.\left[{ }^{18} \mathrm{~F}\right] \mathrm{FDG}\right)$ PET to MIBG in the localization of certain types of pheochromocytomas [29].

One promising newer technique is PET imaging using 6- $\left[{ }^{18} \mathrm{~F}\right]-$ fluorodopamine $\left(\left[{ }^{18} \mathrm{~F}\right]-\mathrm{DA}\right)$, which is able to detect metastatic PCCs with a better sensitivity than ${ }^{123}$ I-MIBG [30, 31]. PET with 6- $\left[{ }^{18} \mathrm{~F}\right]$-fluoroDOPA $\left(\left[{ }^{18} \mathrm{~F}\right]-\mathrm{DOPA}\right)$ can detect extra-adrenal PCCs and neck paragangliomas; unfortunately, these newer techniques are still only available in some selected centers [30-32]. If extra-adrenal or metastatic disease is suspected, bone scan, abdominal and chest CT scan, or ultrasound may determine the extent of disease. Due to the importance of hereditary factors in the development of pheochromocytoma genetic testing is highly recommended. 
There is no curative treatment for PCC, once metastases have occurred. Although reliable data suggesting an improved survival after surgical debulking are lacking, surgical intervention is favored for palliation of local complications due to metastatic disease and reduction of chromaffin tissue and hormonal activity. Surgical debulking may also be used to increase the efficacy of other therapeutic modalities, but again no evidence exists that this therapeutic approach prolongs survival of patients with metastatic disease [16].

In case of a sufficient uptake of ${ }^{123} \mathrm{I}-\mathrm{MIBG}$ treatment with targeted radiation therapy, use of ${ }^{131}$ I-MIBG is an option. External radiation therapy can be utilized in palliation of painful bone metastases. Furthermore, in case of hepatic metastatic lesions treatments such as cryoablation, radiofrequency ablation, or transcatheter arterial embolization are in clinical use $[33,34]$. Although there is no evidence that chemotherapy prolongs the survival of patients with metastatic disease it plays an important rule in the palliation in symptomatic patients. Furthermore, a group of new therapeutic agents, the so-called targeted molecular therapies, represent a highly interesting and promising treatment option.

Besides these specific treatment modalities, medical management of symptoms using adrenergic blockage and catecholamine synthesis inhibition is indicated and will prevent complications from catecholamine excess. a-Adrenoceptor antagonists, dihydropyridine calcium channel receptor blockers, the tyrosine hydroxylase inhibitor a-methyltyrosine, and the competitive $a$ - and $\beta$-receptor blocking drug labetalol have been shown to be effective in the control of blood pressure and other symptoms of pheochromocytoma [35].

The prognosis of malignant PCC remains poor. In patients with metastatic PCC, long-term survival is possible; the overall 5-year survival, however, is less than 50\% [8]. Medical control of the catecholamine excess is mandatory. Surgery, radiation therapy or chemotherapy, and last but not least, the new targeted therapies may provide palliative benefit. In this review, we provide a resume of the current treatment options and future directions in the management of metastatic PCC.

\section{Surgical Treatment}

The surgical approach to malignant pheochromocytoma is not curative, but resection of a primary mass or metastases can reduce hormonal effects on the cardiovascular system and may also be appropriate for lesions present in critical anatomical locations [36]. There are no data documenting that surgical debulking results in improved survival or reduction in symptoms [37]. Due to the metastatic status of malignant PCC there is no curative intention in operative resections [38].

Regarding the difficulties of a perioperative and intraoperative medical management, surgical resections should be placed in experienced hands. Preoperative control of the effect of excessive adrenergic stimulation is necessary and warranted by the use of $a$-adrenergic receptor blockade followed by $\beta$-adrenergic receptor blockade. Preoperatively, the two most commonly administered $a$-adrenergic antagonists are phenoxybenzamine and doxazosin [39]. Furthermore, patients with PCC are in a constant status of volume depletion, due to a permanent inhibition of the renin-angiotensin-aldosterone system. Therefore, a preand intraoperative treatment with volume expansion is required and may prevent postoperative hypotension. Whether i.v. application of some of these drugs (phenoxybenzamine, labetolol) represents a beneficial option, is unclear at present.

Intraoperatively, blood pressure is controlled by titration of small doses of phentolamine or sodium nitroprusside, nitroglycerine, magnesium sulfate, and urapidil. Cardiac arrhythmias are best controlled by short-acting $\beta$-blockers, such as esmolol or the mixed $\alpha-/ \beta$ antagonistic drug labetalol, or antiarrhythmic drugs, such as lidocaine [40, 41]. 
A laparoscopic approach in patients with benign PCC is usually preferred due to less postoperative pain and faster recovery [42]. In contrast to benign PCCs, malignant PCCs often feature large tumors or extra-adrenal tumors in locations difficult to be removed laparoscopically. Therefore, in cases of proven or suspected malignancy open procedures are recommended. The operative approach to malignant PCC includes total adrenalectomy and resection of locoregional lymph nodes or complete excision of paragangliomas and removal of distant metastasis [43]. After the resection of ${ }^{123}$ I-MIBG positive tumor, postoperative ${ }^{131}$ I -MIBG treatment for consolidation is recommended [44].

\section{MIBG-Radiotherapy}

The diagnostic value of metaiodobenzylguanidine has been mentioned above and is based on its structural similarity with noradrenaline and a high affinity to and uptake in chromaffin cells. Up to $60 \%$ of malignant PCC show a positive MIBG-uptake [33, 45].

Since 1983, several studies have investigated the therapeutic option of radiolabeled MIBG in the treatment of malignant neuroendocrine tumors using either single or cumulative doses of ${ }^{131}$ I-MIBG, with a variable total dosage [46]. A retrospective analysis of 19 patients with malignant PCC or paraganglioma revealed an objective tumor response in $47 \%$ after treatment with ${ }^{131}$ I-MIBG with a median initial dose of $7.4 \mathrm{GBq}(200 \mathrm{mCi})$ and a median cumulative dose of $22.2 \mathrm{GBq}(600 \mathrm{mCi})$ [47]. A biochemical response was reported for $67 \%$ and an improvement of symptoms was found in $89 \%$. Overall median follow-up of this patient population was 29 months, with a range of 3-93 months. Toxicity was mostly hematological and was reported in $26 \%$ of patients. Despite a lack of complete tumor response, a palliative treatment effect of ${ }^{131}$ I-MIBG therapy has been noted [48].

Shapiro et al. published data from 28 patients treated with ${ }^{131}$ I-MIBG and showed a partial remission of tumor size in 8 patients and a biochemical PR in 12 patients [49]. There were mild side effects such as radiation sickness (nausea, vomiting, anorexia) occurring in 21 of 28 cases. Minor degrees of hematological toxicity and cases of hypothyroidism were observed in 3 out of 28 .

Besides several case reports [50], an analysis of 37 patients with neuroendocrine tumors, among them 8 metastatic PCCs and 8 metastatic paragangliomas, could confirm an symptomatic improvement as well as a moderate tumor regression or stabilization in $100 \%$, and only showing mild forms of toxicity [44].

Treatment with high-dose ${ }^{131}$ I-MIBG in a number of patients resulted in an objective tumor response in $30 \%$ of patients, stabilization of disease in $57 \%$ of patients, and progression of disease in $13 \%$ of patients. A reduction in catecholamine secretion has been seen in up to $45 \%$ of patients [22].

To improve outcome of a radiotherapeutic approach, some authors used higher levels of activity of ${ }^{131}$ I-MIBG than previously reported [51]. This was based on therapeutic trials with high dose MIBG published for neuroblastomas [52].

Rose et al. escalated the standard dose of ${ }^{131} \mathrm{I}-\mathrm{MIBG}$ as single-treatment of 96 to $300 \mathrm{mCi}$ up to a median single dose of $850 \mathrm{mCi}$. Twelve patients were treated with this regimen, after debulking surgery and stem cell harvest. Three out of 12 patients showed a complete remission and a median follow-up of 45 months (range, 23-101 months). In 7 cases, a partial response was reported, with a median follow-up of 43 months (range, 6-47 months). Two patients showed no response and 2 patients with an initial PR died of progressive disease at 13 and 11 months, respectively. Toxicity was mostly hematological and occurred in $79 \%$ of treatment as grade 3 thrombocytopenia. Furthermore, grade 3 and 4 neutropenia 
was reported in 53\% (10 out of 19) and 19\% (4 out of 19) of treatments, with one patient requiring an autologue stem cell transplantation [51].

A phase II study, published by Fitzgerald et al. in 2006, showed treatment results of 30 patients with malignant PCC or paraganglioma having received a high-dose of MIBG therapy (median dosage $833 \mathrm{mCi}$ ) [53]. All patients had prior surgery; 14 patients were refractory to prior radiation or chemotherapy. In summary, after MIBG-treatment, there were 4 complete remissions, 15 partial remissions, and one stable disease. Five progressive diseases (PDs), 5 initial PRs or SD, with relapse to PD were reported. Overall predicted survival at 5 years was $75 \%$ (Kaplan Meier estimate). According to this study, treatment with high-dose of ${ }^{131}$ I-MIBG produced a sustained CR, PR, or SD in $67 \%$ of patients, with tolerable toxicity.

As with chemotherapy and debulking surgery, treatment with ${ }^{131}$ I-MIBG is no curative option in the treatment of malignant PCC. But it may play an important role as an adjuvant therapeutic agent, following debulking surgery [44].

Combination of ${ }^{131}$ I-MIBG therapy with chemotherapy did not show any convincing results, but an increased toxicity, and cannot be recommended [48]. On the other hand, Hartley et al. reported an increase of ${ }^{123} \mathrm{I}-\mathrm{MIBG}$ uptake after a radiological response to chemotherapy, enabling successful ${ }^{131}$ I-MIBG therapy to follow [54].

Regarding the therapeutic value of MIBG-therapy, studies with higher numbers of patients comparing different therapy modalities, must involve dosimetric studies prior to more substantial recommendations.

\section{Somatostatin Analogues}

The cyclic tetradecapeptide hormone somatostatin, as an inhibitor of GH release from the pituitary gland, is found in the cells of the central and peripheral nervous system as well as in pancreas, adrenal glands, gut, kidney, prostate, placenta, and immune cells [39]. Among different other physiological functions somatostatin also inhibits growth of normal and tumor cells by binding to specific cell surface receptors [55].

Five somatostatin receptor (SSR) subtypes have been described [56]. Neuroendocrine tumors often express somatostatin receptors in high density [57]. Mundschenk et al. specified the receptor subtypes found in adrenal and extra-adrenal PCC and showed a high incidence of particularly SSR-subtype 2A (25\% of PCC) and 3 (90\% of PCC) [56, 58].

Since natural somatostatin peptides exhibit a very short half-life, stable somatostatin analogues like octreotide, lanreotide, and pasireotide have been developed and are employed in the treatment of SSR-positive neuroendocrine tumors [59,60]. The therapeutic use of octreotide may lead to a stabilization of NET-progression by inhibition of growth factors like IGF-I and anti-angiogenesis effects [61].

Besides the therapeutic option, somatostatin analogues are also used for diagnostic testing. Somatostatin receptor imaging (SRI) using radiolabeled octreotide such as ${ }^{11} 1_{\text {indium (In)- }}$ octreotide has a high sensitivity, especially for localizing head and neck paragangliomas [45, $62,63]$. In a study of 29 patients suffering from head and neck paragangliomas, octreotide scintigraphy showed positive results in 27 cases, with a sensitivity of $93 \%$. In contrast to the octreotide scintigraphy, the MIBG-scan was only positive in 13 patients [62].

An analysis of 14 patients with malignant PCC or paraganglioma, published by Tenenbaum et al., showed 3 patients with more than 20 tumor sites on MIBG scans in contrast to 1-9 
sites on ${ }^{111}$ In-octreotide scintigraphy. Two of the 14 patients had no MIBG uptake, but one had lung uptake on octreotide scintigraphy. Although the uptake intensity and number of tumor sites of MIBG-scan was superior to ${ }^{111} \mathrm{In}$-octreotide, seven foci were only found by octreotide scintigraphy. The authors suggested a diagnostic benefit in the combination of ${ }^{123} \mathrm{I}$-MIBG und ${ }^{111}$ In-octreotide scintigraphy, in terms of detection of chromaffin tissue. In summary, the diagnostic value of octreotide-scans in metastatic neuroendocrine carcinoma is considered rather complementary than superior to MIBG-scan [45].

The therapeutic effect of treating metastatic neuroendocrine tumors with SS-analogues in case of positive octreotide-scan has been analyzed in several studies with small patient numbers. Thus, the short-term administration of low-dose octreotide $(50 \mu \mathrm{g})$ for $2 \mathrm{~h}$ in 6 patients with chromaffin cell tumors showed a decrease of catecholamine levels, but did not yield to a consistent effect [59]. Another prospective study on 10 patients with malignant or recurrent pheochromocytomas examined the treatment success of intramuscular injections of $20 \mathrm{mg}$ slow-release octreotide, administered thrice monthly [64]. The patients were screened by SSR-scintigraphy using ${ }^{111} \mathrm{In}$-pentetreotide prior to therapy. There was no difference in plasma or urinary catecholamine levels, blood pressure or chromogranin A concentration between patients with positive SSR-scan and those whose tumors were negative. These results confirmed the analysis of the same group in 1995 demonstrating no significant treatment effect with $100 \mu \mathrm{g}$ octreotide in patients with PCC [65].

In the last few years, a radiotherapeutic approach with radiolabeled somatostatin analogues like ${ }^{177}$ lutetium (Lu)-DOTA-octreotide, and ${ }^{90}$ yttrium (Y)-DOTA-lanreotide has been established for the treatment of metastatic neuroendocrine tumors. Twenty patients with metastatic nonresectable NETs, including one paraganglioma, treated with ${ }^{90} \mathrm{Y}$-DOTAlanreotide showed a partial remission in 5 cases; stable disease could be achieved in 11 patients and 4 patients showed tumor progression. No serious adverse events were noted [57].

Forrer et al. published data from 28 patients with metastatic paraganglioma and PCC receiving a radiotherapeutic regimen with the radiolabeled somatostatin analogue [DOTA$\operatorname{Tyr}(3)$ ]-octreotide (DOTATOC) [66]. Twenty-five patients were treated with a total of 200 $\mathrm{mCi} / \mathrm{m}(2)$ body surface $\left[{ }^{90} \mathrm{Y}\right]$ DOTATOC, 3 patients for one cycle with $100 \mathrm{mCi} / \mathrm{m}(2)$ $\left[{ }^{90} \mathrm{Y}\right]$ DOTATOC followed by 2 cycles of $200 \mathrm{mCi}$ [177Lu]DOTATOC. There was no severe toxicity reported. A partial remission was found in 2 patients and 5 had a minor response. There were 13 stable diseases, 2 mixed responses, and 6 patients remained progressive. With a follow-up ranging from 6 to 50 months, time to progression is documented from 3 to $>42$ months. Ten responses, 9 stable diseases and one partial remission, are still ongoing. Based on this data, the authors conclude an effectiveness of DOTATOC treatment in patients with somatostatin receptor positive PCC or paraganglioma [66].

Novel somatostatin analogues such as pasireotide (SOM230) have been investigated in current studies [67]. A comparative analysis showed superior effects of treatment with SOM230 versus octreotide (OCT) in primary PCC cell cultures, concerning the reduction of catecholamine levels, modulation of cell growth, and apoptosis [68]. There are still trials ongoing examining the possibility of therapeutic options of SOM230 in malignant PCC.

\section{Chemotherapy}

Systemic antineoplastic treatment plays an important role in metastatic PCC with numerous cytoreductive agents available. Several single agents and drug combinations have been used with variable success. The optimal systemic treatment for metastatic disease has not been well defined, due to a lack of randomized studies comparing different regimens in a large 
number of patients. In addition, there are many case reports and data on small number of patients having combined chemotherapy with radiotherapeutic treatment, making single drug effects difficult to define [17].

The majority of published regimens includes alkylating agents like cyclophosphamide, which has been shown to produce a significant reduction of catecholamine excretion [43]. A therapeutic regimen of cyclophosphamide and methotrexate combined with radiotherapy was not effective in a case of orbital metastases of a malignant PCC [69]. Another approach, published in 1976, used vincristine and cyclophosphamide, combined with radiotherapy for a young patient suffering from a metastatic PCC. The author noted a decrease in the patient's condition after 24 weeks; after changing the therapy regimen to doxorubicinemono, the patient died after 2 courses of a pseudomonas' lung infection and sepsis [70].

As a first important cytostatic approach, the use of streptozotocin in monotherapy and in combination with different agents was employed with variable results [71-73]. Two patients with metastatic PCC received chemotherapy with 5-fluorouracil, cyclophosphamide, and streptozotocin and achieved a biochemical response in one instance [74]. The therapeutic use of platinum derivatives was published in single case reports with different results [75, 76].

The most effective chemotherapy regimen appears to be the combination of cyclophosphamide ( $750 \mathrm{mg} / \mathrm{qm} \mathrm{d} 1)$, vincristine $(1.4 \mathrm{mg} / \mathrm{qm} \mathrm{d} 1)$, and dacarbazine (600 mg/ qm d1 + 2), the so-called CVD-protocol, which was introduced by Keiser et al. in 1985 [77]. A nonrandomized study, published in 1988, was able to show either partial or complete response with a mean duration of 21 months in up to $50 \%$ of 14 patients with malignant PCC treated with the CVD-scheme [37]. Responding patients showed an improved Karnofsky score and decreased need of antihypertensive medication, due to a measurable reduction of catecholamine secretion. Only one patient suffered from progressive disease during antineoplastic therapy. Toxicity did not occur in a severe way and included hematologic, neurologic, and gastrointestinal effects [37]. There are several case reports confirming a therapeutic success achieved by the CVD-protocol $[78,79]$.

Similar to a surgical approach, CVD can induce hypertensive crises, therefore combined treatment with a-methyl- $p$-tyrosine to inhibit catecholamine synthesis prior to chemotherapy has been recommended [80]. a-Methyl- $p$-tyrosine is a competitive inhibitor of tyrosine hydroxylase, the enzyme catalyzing the conversion of tyrosine to dihydroxyphenylalanine, the first step in the catecholamine synthesis. An addition of anthracycline to the CVDprotocol was published in one case report and led to a complete remission continued 3 years after cessation [36].

A 22-year follow-up of 18 of patients with a diagnosis of pheochromocytoma/ paraganglioma treated with the CVD-protocol was published last year. Complete remission was evident in $11 \%$ and partial remission in $44 \%$. Responding patients had a median overallsurvival of 3.8 years, whereas nonresponders showed a median survival of 1.8 years. According to the small number of patients in this study, the difference was not statistically significant $(p=0.65)$ [81]. Chemotherapy was well tolerated with only grade I/II toxicities.

Merging the published data, no evidence exists that any published chemotherapy regime prolongs the survival of patients with metastatic disease in a significant way. However, CVD has been shown to produce partial remissions and in single cases complete remissions, to improve symptoms and rarely, to lead to tumor shrinkage that made surgical resection possible. 
Thus, published data suggests that chemotherapy may be useful for palliation in symptomatic patients and may improve the prognosis of the tumor. It is also clearly apparent that once the patient has started on chemotherapy, this treatment modality should be continued indefinitely, if tolerated.

In 2006, a phase II study of the therapeutic efficacy and toxicity of an oral combined therapy with temozolomide and thalidomide in patients with metastatic carcinoid, pheochromocytoma, or pancreatic neuroendocrine tumors was published [82].

Temozolomide is an alkylating agent, achieving its antineoplastic activity through the active compound, MTIC (monomethyl triazenoimidazole carboxamide) and can - in contrast to its derivate dacarbazine - be orally administered. Furthermore, being able to cross the bloodbrain-barrier, temozolomide is used in the treatment of intracerebral metastasis [83]. Because of the co-employment of the angiogenesis inhibitor thalidomide, the results of this therapy study will be discussed in the chapter "Targeted Therapies" below.

Another retrospective analysis of the effect of a monotherapy with temozolomide in advanced neuroendocrine tumors has been published in 2007 [84]. Thirty-six pretreated patients with inoperable and/or metastatic neuroendocrine tumor (1 gastric, 7 thymic and 13 bronchial carcinoids, 12 pancreatic endocrine tumors, 1 paraganglioma, 1 neuroendocrine foregut, and 1 neuroendocrine cecal cancer) were treated with temozolomide [200 mg/m(2)] for 5 days every 4 weeks. Overall radiologic response rate was 14\%, with up to $50 \%$ of 37 patients achieving a stable disease. Median overall time to progression was 7 months. Toxicity was moderate and mainly hematologic with a grade III/IV thrombocytopenia in $14 \%$ [84]. Regarding a palliative therapy situation, temozolomide as monotherapy may be a therapeutic option for patients with advanced neuroendocrine tumors. Although there was only one case with paraganglioma included in this study, the results can be seen as mildly promising for patients with malignant PCC or paraganglioma.

\section{Targeted Therapies}

As in many tumor entities during the last decade, novel antineoplastic agents - the so-called "targeted therapies" - have been employed in patients with malignant PCC. This group of cytostatic therapies is a radically new approach to drug treatment of malignant neoplasms achieving its antineoplastic activity by interfering with specific targeted molecules needed for carcino-genesis and tumor growth. Most of these agents do not show a mere cytotoxic activity, but exert cytostatic effects through inhibition of mechanisms responsible for the formation of a malignant phenotype.

Histological, immunihistochemical as well as molecular analyses of chromaffin cells in tumors have revealed high expression, especially in malignant tumors of vascular endothelial growth factor (VEGF), endothelin receptor type A and B, and components of the telomerase complex, the heat shock protein 90 (HSP90) [85]. Cyclo-oxygenase and Ncadherin were also over-expressed in malignant PCC $[11,12]$.

In fact, none of these markers are specific for malignancy and may only be used as indicators in the distinction between malignant and benign PCC, but they are promising and important targets for new effective treatment modalities.

Sunitinib and Sorafenib are potent tyrosine kinase inhibitors targeting vascular endothelial growth factor, platelet derived growth factor, RET, c-KIT and FLT-3 receptors having achieved an important therapeutic role, for example, in the treatment of metastatic renal cancer [86]. 
Recently, some studies reported promising therapy results of a treatment with sunitinib in patients with metastatic neuroendocrine carcinoma. Jimenez et al. reported that one patient with advanced PCC occurring within a VHL-syndrome, has achieved a radiologic partial remission, an improvement of his performance status and normalization of blood pressure due to decreased catecholamine levels after 6 months of therapy with sunitinib [87]. This was confirmed by a small series study of 3 patients with malignant paraganglioma reporting one very good partial remission and 2 PR induced by a therapy with sunitinib at a standard dose (50 mg daily, 4 weeks on, 2 weeks off) [88]. Currently, the published data are limited to only a few case reports, but phase II studies are ongoing.

The VEGF-inhibitor thalidomide in combination with temozolomide was tested for the treatment of metastatic neuroendocrine carcinoma. In a phase II study, 29 patients were treated with a regimen of temozolomide ( $150 \mathrm{mg} / \mathrm{qm}$ for $7 \mathrm{~d}$ ) and thalidomide (50-400 mg daily) [82]. An objective biochemical response by a decrease of chromogranin A was found in $40 \%$, and a radiologic response rate in $25 \%$ among all patients ( $45 \%$ among pancreatic endocrine tumors, $33 \%$ among pheochromocytomas, and $7 \%$ among carcinoid tumors). The median time to progression was 13.5 months, 1-year survival was 79\%, and 2-year survival was $61 \%$. Side effects were mainly hematologic. Thus, $69 \%$ of patients developed grade 3-4 lymphopenia, which caused grave opportunistic infections in three patients (10\%). Still, it is too premature to deduce a promising novel therapeutic strategy for malignant PCC from these data, with only one PCC patient included in this trial.

Therapeutic trials in metastatic neuroendocrine carcinoma with increased expression of c-kit and/of PDGF-R, using imatinib mesylate, an inhibitor of tyrosine kinase, did not reveal positive results [89]. Imatinib was administered at a standard dose $(400 \mathrm{mg} /$ day, with possible dose escalation) to 15 adult patients with metastatic endocrine tumors, 2 malignant PCC, 2 carcinoids, and one neuroendocrine tumor (NET), respectively. No tumor entity showed an objective response. Patients with malignant PCC and NET suffered from progressive disease when treated with imatinib. One patient with carcinoid achieved a stable disease for 6.5 months, whereas the other one showed progress. Furthermore, reporting significant toxicity in this patient population the authors concluded that there is no therapy recommendation for imatinib mesylate to patients with malignant endocrine tumors.

Everolimus (RAD001), an mTOR (mammalian target of rapamycin) inhibitor, has shown different treatment results in patients with neuroendocrine tumors. An attempt in two patients with malignant paraganglioma was unsuccessful [85], whereas a phase II study of advanced low- or intermediate-grade neuroendocrine tumors treated with everolimus in combination with octreotide-LAR showed $22 \%$ partial responses (22\%), $70 \%$ stable disease (SD, 70\%), and 8\% progressive disease (8\%) [90]. The overall median progression-free survival (PFS) was 60 weeks. Thus, treatment trials with everolimus are ongoing.

Regarding the overexpression of HSP90 in malignant pheochromocytomas, the new inhibitor of this protein 17-allylamino,17-demethoxygeldanamycin may have therapeutic potential, but currently therapy studies are lacking [91].

Table 1 shows some selected novel substances bearing potential for the treatment of neuroendocrine tumors including malignant PCC. With the advent of these new molecular targeted therapies the systemic treatment of malignant PCC has achieved an important and promising widening. Recently published results encourage additional clinical evaluations improving the prognosis of this disease. 


\section{Conclusions and Recommendations}

Currently, there are no curative therapy options for malignant PCCs. Another difficulty in defining a treatment algorithm is caused by the lack of valid studies comparing different therapy modalities in a significantly high number of patients and in a randomized, controlled fashion. Nevertheless, some important and forward-looking studies analyzing different therapy regimens have been published.

As most treatments are palliative and due to the unfavorable prognosis, assuring quality of life is the main objective in patients suffering from metastatic PCCs. Because of the heterogeneity of the disease, there are many factors like index of proliferation, MIBGpositivity or operability influencing the treatment decision. Therefore, once the diagnosis is confirmed, the localization and extent of disease should be determined. Patients with metastatic chromaffin-cell tumors should be examined by scintigraphy to evaluate the possibility of ${ }^{131}$ I-MIBG therapy [33, 45].

Besides a long-term medical treatment of symptoms using selective $a-1$ blockers and nonselective, noncompetitive $a$ - and/or $\beta$-blockers in patients with hormonally active tumors, debulking surgery is the first treatment step. Although no evidence exists that debulking surgery prolongs survival, it may alleviate symptoms by reducing tumor mass and may also increase the efficacy of following therapeutic modalities. In case of liver lesions other ablative procedures, like arterial embolization or chemoembolisztion of hepatic metastases should also be considered [34].

In the absence of a curative therapy, a strategy of wait and watch may be an option in case of very low proliferation index. These patients should receive a specific therapy only in case of progression. Sixty percent of malignant PCCs sites show a positive ${ }^{131}$ I-MIBG uptake [53]. Featuring a moderate progression, these patients may benefit from a ${ }^{131} \mathrm{I}-\mathrm{MIBG}$ therapy, which can achieve substantial tumor responses and possibly an elimination of micrometastases. Treatment with a high dose of ${ }^{131}$ I-MIBG have shown convincing results $[52,53]$, but currently there is no clear recommendation regarding a particular dosage of radionuclide.

Chemotherapy should be applied to patients without positive MIBG-scan, with no response to ${ }^{131}$ I-MIBG or progression after radionuclide treatment, and especially in cases with high proliferation index. Several chemotherapy regimens have been tested in patients with metastatic PCC [71-74, 76]. Currently, the most effective chemotherapy regimen appears to be the CVD-scheme [77-79, 92]. Combination of ${ }^{131}$ I-MIBG therapy with chemotherapy did not show any benefit, but as it is accompanied by increased toxicity, it may not be recommended. Instead, a sequential approach should be considered.

Interestingly, a group of novel antineoplastic therapies, the so-called targeted therapies, have also found their way in the treatment of malignant PCCs. For instance, treatment combinations of temozolomide and thalidomide have shown encouraging results. Furthermore, therapy including sunitinib or novel therapeutic somatostatin analogues revealed promising response rates in patients with metastatic PCCs. Fig. 1 depicts the suggested treatment algorithm of malignant pheochromocytoma/paraganglioma.

Besides determining an optimum treatment regimen containing chemotherapy and radionuclide therapy through multicenter randomized trials, these novel substances should increasingly be included in future treatment studies, with the aim of reaching a widely accepted consensus on the treatment of malignant PCCs. 


\section{References}

1. Manger WM. An overview of pheochromocytoma: history, current concepts, vagaries, and diagnostic challenges. Ann N Y Acad Sci. 2006; 1073:1-20. [PubMed: 17102067]

2. McNeil AR, Blok BH, Koelmeyer TD, Burke MP, Hilton JM. Phaeochromocytomas discovered during coronial autopsies in Sydney, Melbourne and Auckland. Aust N Z J Med. 2000; 30:648-652. [PubMed: 11198571]

3. Neumann HP, Bausch B, McWhinney SR, Bender BU, Gimm O, Franke G, Schipper J, Klisch J, Altehoefer C, Zerres K, Januszewicz A, Eng C, Smith WM, Munk R, Manz T, Glaesker S, Apel TW, Treier M, Reineke M, Walz MK, Hoang-Vu C, Brauckhoff M, Klein-Franke A, Klose P, Schmidt H, Maier-Woelfle M, Peczkowska M, Szmigielski C. Germ-line mutations in nonsyndromic pheochromocytoma. N Engl J Med. 2002; 346:1459-1466. [PubMed: 12000816]

4. Tischler AS. Pheochromocytoma and extra-adrenal paraganglioma: updates. Arch Pathol Lab Med. 2008; 132:1272-1284. [PubMed: 18684026]

5. Strong VE, Kennedy T, Al Ahmadie H, Tang L, Coleman J, Fong Y, Brennan M, Ghossein RA. Prognostic indicators of malignancy in adrenal pheochromocytomas: clinical, histopathologic, and cell cycle/apoptosis gene expression analysis. Surgery. 2008; 143:759-768. [PubMed: 18549892]

6. Thompson LD. Pheochromocytoma of the Adrenal gland Scaled Score (PASS) to separate benign from malignant neoplasms: a clinicopathologic and immunophenotypic study of 100 cases. Am J Surg Pathol. 2002; 26:551-566. [PubMed: 11979086]

7. Wu LT, Dicpinigaitis P, Bruckner H, Manger W, Averbuch S. Hypertensive crises induced by treatment of malignant pheochromocytoma with a combination of cyclophosphamide, vincristine, and dacarbazine. Med Pediatr Oncol. 1994; 22:389-392. [PubMed: 8152400]

8. Goldstein RE, O'Neill JA Jr, Holcomb GW III, Morgan WM III, Neblett WW III, Oates JA, Brown N, Nadeau J, Smith B, Page DL, Abumrad NN, Scott HW Jr. Clinical experience over 48 years with pheochromocytoma. Ann Surg. 1999; 229:755-764. [PubMed: 10363888]

9. Scholz T, Schulz C, Klose S, Lehnert H. Diagnostic management of benign and malignant pheochromocytoma. Exp Clin Endocrinol Diabetes. 2007; 115:155-159. [PubMed: 17427102]

10. Favier J, Plouin PF, Corvol P, Gasc JM. Angiogenesis and vascular architecture in pheochromocytomas: distinctive traits in malignant tumors. Am J Pathol. 2002; 161:1235-1246. [PubMed: 12368197]

11. Salmenkivi K, Haglund C, Arola J, Heikkila P. Increased expression of tenascin in pheochromocytomas correlates with malignancy. Am J Surg Pathol. 2001; 25:1419-1423. [PubMed: 11684959]

12. Salmenkivi K, Heikkila P, Liu J, Haglund C, Arola J. VEGF in 105 pheochromocytomas: enhanced expression correlates with malignant outcome. APMIS. 2003; 111:458-464. [PubMed: 12780519]

13. Amar L, Bertherat J, Baudin E, Ajzenberg C, Bressac-de Paillerets B, Chabre O, Chamontin B, Delemer B, Giraud S, Murat A, Niccoli-Sire P, Richard S, Rohmer V, Sadoul JL, Strompf L, Schlumberger M, Bertagna X, Plouin PF, Jeunemaitre X, Gimenez-Roqueplo AP. Genetic testing in pheochromocytoma or functional paraganglioma. J Clin Oncol. 2005; 23:8812-8818. [PubMed: 16314641]

14. Rao F, Keiser HR, O'Conner DT. Malignant pheochromocytoma. Chromaffi n granule transmitters and response to treatment. Hypertension. 2000; 36:1045-1052. [PubMed: 11116123]

15. Capella C, Riva C, Cornaggia M, Chiaravalli AM, Frigerio B, Solcia E. Histopathology, cytology and cytochemistry of pheochromocytomas and paragangliomas including chemodectomas. Pathol Res Pract. 1988; 183:176-187. [PubMed: 2838831]

16. Eisenhofer G, Bornstein SR, Brouwers FM, Cheung NK, Dahia PL, de Krijger RR, Giordano TJ, Greene LA, Goldstein DS, Lehnert H, Manger WM, Maris JM, Neumann HP, Pacak K, Shulkin BL, Smith DI, Tischler AS, Young WF Jr. Malignant pheochromocytoma: current status and initiatives for future progress. Endocr Relat Cancer. 2004; 11:423-436. [PubMed: 15369446]

17. Neumann HP, Berger DP, Sigmund G, Blum U, Schmidt D, Parmer RJ, Volk B, Kirste G. Pheochromocytomas, multiple endocrine neoplasia type 2, and von Hippel-Lindau disease. N Engl J Med. 1993; 329:1531-1538. [PubMed: 8105382] 
18. Tanaka S, Ito T, Tomoda J, Higashi T, Yamada G, Tsuji T. Malignant pheochromocytoma with hepatic metastasis diagnosed 20 years after resection of the primary adrenal lesion. Intern Med. 1993; 32:789-794. [PubMed: 8012074]

19. Pommier RF, Vetto JT, Billingsly K, Woltering EA, Brennan MF. Comparison of adrenal and extraadrenal pheochromocytomas. Surgery. 1993; 114:1160-1165. [PubMed: 8256223]

20. Sclafani LM, Woodruff JM, Brennan MF. Extraadrenal retroperitoneal paragangliomas: natural history and response to treatment. Surgery. 1990; 108:1124-1129. [PubMed: 2174194]

21. Whalen RK, Althausen AF, Daniels GH. Extra-adrenal pheochromocytoma. J Urol. 1992; 147:110. [PubMed: 1729490]

22. Loh KC, Fitzgerald PA, Matthay KK, Yeo PP, Price DC. The treatment of malignant pheochromocytoma with iodine-131 metaiodobenzylguanidine (131I-MIBG): a comprehensive review of 116 reported patients. J Endocrinol Invest. 1997; 20:648-658. [PubMed: 9492103]

23. Eisenhofer G, Siegert G, Kotzerke J, Bornstein SR, Pacak K. Current progress and future challenges in the biochemical diagnosis and treatment of pheochromocytomas and paragangliomas. Horm Metab Res. 2008; 40:329-337. [PubMed: 18491252]

24. Lenders JW, Keiser HR, Goldstein DS, Willemsen JJ, Friberg P, Jacobs MC, Kloppenborg PW, Thien T, Eisenhofer G. Plasma metanephrines in the diagnosis of pheochromocytoma. Ann Intern Med. 1995; 123:101-109. [PubMed: 7778821]

25. Sjoberg RJ, Simcic KJ, Kidd GS. The clonidine suppression test for pheochromocytoma. A review of its utility and pitfalls. Arch Intern Med. 1992; 152:1193-1197. [PubMed: 1599347]

26. Cleary S, Phillips JK, Huynh TT, Pacak K, Fliedner S, Elkahloun AG, Munson P, Worrell RA, Eisenhofer G. Chromogranin a expression in phaeochromocytomas associated with von HippelLindau syndrome and multiple endocrine neoplasia type 2. Horm Metab Res. 2007; 39:876-883. [PubMed: 18046660]

27. Grossrubatscher E, Dalino P, Vignati F, Gambacorta M, Pugliese R, Boniardi M, Rossetti O, Marocchi A, Bertuzzi M, Loli P. The role of chromogranin A in the management of patients with phaeochromocytoma. Clin Endocrinol (Oxf). 2006; 65:287-293. [PubMed: 16918946]

28. Havekes B, Lai EW, Corssmit EP, Romijn JA, Timmers HJ, Pacak K. Detection and treatment of pheochromocytomas and paragangliomas: current standing of MIBG scintigraphy and future role of PET imaging. Q J Nucl Med Mol Imaging. 2008; 52:419-429. [PubMed: 19088695]

29. Takano A, Oriuchi N, Tsushima Y, Taketomi-Takahashi A, Nakajima T, Arisaka Y, Higuchi T, Amanuma M, Endo K. Detection of metastatic lesions from malignant pheochromocytoma and paraganglioma with diff usion-weighted magnetic resonance imaging: comparison with 18F-FDG positron emission tomography and 123I-MIBG scintigraphy. Ann Nucl Med. 2008; 22:395-401. [PubMed: 18600417]

30. Ilias I, Chen CC, Carrasquillo JA, Whatley M, Ling A, Lazurova I, Adams KT, Perera S, Pacak K. Comparison of 6-18F-fl uorodopamine PET with 123I-metaiodobenzylguanidine and 111Inpentetreotide scintigraphy in localization of nonmetastatic and metastatic pheochromocytoma. $\mathrm{J}$ Nucl Med. 2008; 49:1613-1619. [PubMed: 18794260]

31. Timmers HJ, Eisenhofer G, Carrasquillo JA, Chen CC, Whatley M, Ling A, Adams KT, Pacak K. Use of 6-[18F]-fl uorodopamine positron emission tomography as fi rst-line investigation for the diagnosis and localization of non-metastatic and metastatic pheochromocytoma. Clin Endocrinol (Oxf). Dec 5.2008 [Epub ahead of print].

32. Hoegerle S, Nitzsche E, Altehoefer C, Chen CC, Whatley M, Ling A, Adams KT, Pacak K. Pheochromocytomas: detection with 18F DOPA whole body PET-initial results. Radiology. 2002; 222:507-512. [PubMed: 11818620]

33. Pacak K, Ilias I, Adams KT, Eisenhofer G. Biochemical diagnosis, localization and management of pheochromocytoma: focus on multiple endocrine neoplasia type 2 in relation to other hereditary syndromes and sporadic forms of the tumour. J Intern Med. 2005; 257:60-68. [PubMed: 15606377]

34. Takahashi K, Ashizawa N, Minami T, Suzuki S, Sakamoto I, Hayashi K, Tomiyasu S, Sumikawa K, Kitamura K, Eto T, Yano K. Malignant pheochromocytoma with multiple hepatic metastases treated by chemotherapy and transcatheter arterial embolization. Intern Med. 1999; 38:349-354. [PubMed: 10361908] 
35. Tada K, Okuda Y, Yamashita K. Three cases of malignant pheochromocytoma treated with cyclophosphamide, vincristine, and dacarbazine combination chemotherapy and alpha-methyl-ptyrosine to control hypercatecholaminemia. Horm Res. 1998; 49:295-297. [PubMed: 9623522]

36. Nonaka K, Makuuchi H, Naruse Y, Kobayashi T, Goto M. Surgical excision of malignant pheochromocytoma in the left atrium. Jpn J Thorac Cardiovasc Surg. 2000; 48:126-128. [PubMed: 10769996]

37. Huang KH, Chung SD, Chen SC, Chueh SC, Pu YS, Lai MK, Lin WC. Clinical and pathological data of 10 malignant pheochromocytomas: longterm follow up in a single institute. Int J Urol. 2007; 14:181-185. [PubMed: 17430251]

38. Ahlman H. Malignant pheochromocytoma: state of the fi eld with future projections. Ann N Y Acad Sci. 2006; 1073:449-464. [PubMed: 17102114]

39. Mannelli M. Management and treatment of pheochromocytomas and paragangliomas. Ann N Y Acad Sci. 2006; 1073:405-416. [PubMed: 17102109]

40. Brauckhoff M, Gimm O, Dralle H. Preoperative and surgical therapy in sporadic and familial pheochromocytoma. Front Horm Res. 2004; 31:121-144. [PubMed: 14674308]

41. Lehnert H, Mundschenk J, Hahn K. Malignant pheochromocytoma. Front Horm Res. 2004; 31:155-162. [PubMed: 14674310]

42. Jaroszewski DE, Tessier DJ, Schlinkert RT, Grant CS, Thompson GB, van Heerden JA, Farley DR, Smith SL, Hinder RA. Laparoscopic adrenalectomy for pheochromocytoma. Mayo Clin Proc. 2003; 78:1501-1504. [PubMed: 14661679]

43. Joseph L. Malignant phaochromocytoma of the organ of Zuckerkandl with functioning metastases. Br J Urol. 1967; 39:221-225. [PubMed: 6025400]

44. Mukherjee JJ, Kaltsas GA, Islam N, Plowman PN, Foley R, Hikmat J, Britton KE, Jenkins PJ, Chew SL, Monson JP, Besser GM, Grossman AB. Treatment of metastatic carcinoid tumours, phaeochromocytoma, paraganglioma and medullary carcinoma of the thyroid with (131)I-metaiodobenzylguanidine [(131)I-mIBG]. Clin Endocrinol (Oxf). 2001; 55:47-60. [PubMed: 11453952]

45. van der HE, de Herder WW, Bruining HA, Bonjer HJ, de Krijger RR, Lamberts SW, van de Meiracker AH, Boomsma F, Stijnen T, Krenning EP, Bosman FT, Kwekkeboom DJ. [(123)I]metaiodobenzylguanidine and [(111)In]octreotide uptake in benign and malignant pheochromocytomas. J Clin Endocrinol Metab. 2001; 86:685-693. [PubMed: 11158032]

46. Sisson JC, Shapiro B, Beierwaltes WH, Glowniak JV, Nakajo M, Mangner TJ, Carey JE, Swanson DP, Copp JE, Satterlee WG. Radiopharmaceutical treatment of malignant pheochromocytoma. J Nucl Med. 1984; 25:197-206. [PubMed: 6726430]

47. Gedik GK, Hoefnagel CA, Bais E, Olmos RA. 131I-MIBG therapy in metastatic phaeochromocytoma and paraganglioma. Eur J Nucl Med Mol Imaging. 2008; 35:725-733. [PubMed: 18071700]

48. Kaltsas GA, Mukherjee JJ, Foley R, Britton KE, Grossman AB. Treatment of Metastatic Pheochromocytoma and Paraganglioma With 131I-Meta-Iodobenzylguanidine (MIBG). Endocrinologist. 2001; 13:321-333.

49. Shapiro B, Sisson JC, Wieland DM, Mangner TJ, Zempel SM, Mudgett E, Gross MD, Carey JE, Zasadny KR, Beierwaltes WH. Radiopharmaceutical therapy of malignant pheochromocytoma with 131I-metaiodobenzylguanidine: results from ten years of experience. J Nucl Biol Med. 1991; 35:269-276. [PubMed: 1823834]

50. Troncone L, Rufini V. 131I-MIBG therapy of neural crest tumours (review). Anticancer Res. 1997; 17:1823-1831. [PubMed: 9179240]

51. Rose B, Matthay KK, Price D, Huberty J, Klencke B, Norton JA, Fitzgerald PA. High-dose 131Imetaiodobenzylguanidine therapy for 12 patients with malignant pheochromocytoma. Cancer. 2009; 98:239-248. [PubMed: 12872341]

52. Matthay KK, DeSantes K, Hasegawa B, Huberty J, Hattner RS, Ablin A, Reynolds CP, Seeger RC, Weinberg VK, Price D. Phase I dose escalation of 131I-metaiodobenzylguanidine with autologous bone marrow support in refractory neuroblastoma. J Clin Oncol. 1998; 16:229-236. [PubMed: 9440747] 
53. Fitzgerald PA, Goldsby RE, Huberty JP, Price DC, Hawkins RA, Veatch JJ, Dela Cruz F, Jahan TM, Linker CA, Damon L, Matthay KK. Malignant pheochromocytomas and paragangliomas: a phase II study of therapy with high-dose 131I-metaiodobenzylguanidine (131I-MIBG). Ann N Y Acad Sci. 2006; 1073:465-490. [PubMed: 17102115]

54. Hartley A, Spooner D, Brunt AM. Management of malignant phaeochromocytoma: a retrospective review of the use of MIBG and chemotherapy in the West Midlands. Clin Oncol (R Coll Radiol). 2001:361-366. [PubMed: 11716230]

55. Weckbecker G, Raulf F, Stolz B, Bruns C. Somatostatin analogs for diagnosis and treatment of cancer. Pharmacol Ther. 1993; 60:245-264. [PubMed: 7912834]

56. Patel YC. Somatostatin and its receptor family. Front Neuroendocrinol. 1999; 20:157-198. [PubMed: 10433861]

57. Frilling A, Weber F, Saner F, Bockisch A, Hofmann M, Mueller-Brand J, Broelsch CE. Treatment with (90)Y- and (177)Lu-DOTATOC in patients with metastatic neuroendocrine tumors. Surgery. 2006; 140:968-976. [PubMed: 17188146]

58. Hubalewska-Dydejczyk A, Trofimiuk M, Sowa-Staszczak A, Gilis-Januszewska A, Wierzchowski W, Pach D, Budzynski A, Karcz D. Somatostatin receptors expression (SSTR1-SSTR5) in pheochromocytomas. Przegl Lek. 2008; 65:405-407. [PubMed: 19140390]

59. Invitti C, De MI, Bolla GB, Pecori Giraldi F, Maestri E, Leonetti G, Cavagnini F. Effect of octreotide on catecholamine plasma levels in patients with chromaffi n cell tumors. Horm Res. 1993; 40:156-160. [PubMed: 8300064]

60. Mundschenk J, Unger N, Schulz S, Hollt V, Schulz S, Steinke R, Lehnert H. Somatostatin receptor subtypes in human pheochromocytoma: subcellular expression pattern and functional relevance for octreotide scintigraphy. J Clin Endocrinol Metab. 2003; 88:5150-5157. [PubMed: 14602742]

61. Arnold R, Trautmann ME, Creutzfeldt W, Benning R, Benning M, Neuhaus C, Jurgensen R, Stein K, Schafer H, Bruns C, Dennler HJ. Somatostatin analogue octreotide and inhibition of tumour growth in metastatic endocrine gastroenteropancreatic tumours. Gut. 1996; 38:430-438. [PubMed: 8675099]

62. Koopmans KP, Jager PL, Kema IP, Kerstens MN, Albers F, Dullaart RP. 111In-octreotide is superior to 123I-metaiodobenzylguanidine for scintigraphic detection of head and neck paragangliomas. J Nucl Med. 2008; 49:1232-1237. [PubMed: 18632829]

63. Shulkin BL, Ilias I, Sisson JC, Pacak K. Current trends in functional imaging of pheochromocytomas and paragangliomas. Ann N Y Acad Sci. 2006; 1073:374-382. [PubMed: 17102106]

64. Lamarre-Cliche M, Gimenez-Roqueplo AP, Billaud E, Baudin E, Luton JP, Plouin PF. Effects of slow-release octreotide on urinary metanephrine excretion and plasma chromogranin A and catecholamine levels in patients with malignant or recurrent phaeochromocytoma. Clin Endocrinol (Oxf). 2002; 57:629-634. [PubMed: 12390337]

65. Plouin PF, Bertherat J, Chatellier G, Billaud E, Azizi M, Grouzmann E, Epelbaum J. Short-term effects of octreotide on blood pressure and plasma catecholamines and neuropeptide Y levels in patients with phaeochromocytoma: a placebo-controlled trial. Clin Endocrinol (Oxf). 1995; 42:289-294. [PubMed: 7758234]

66. Forrer F, Riedweg I, Maecke HR, Mueller-Brand J. Radiolabeled DOTATOC in patients with advanced paraganglioma and pheochromocytoma. Q J Nucl Med Mol Imaging. 2008; 52:334-340. [PubMed: 18480742]

67. Bruns C, Lewis I, Briner U, Meno-Tetang G, Weckbecker G. SOM230: a novel somatostatin peptidomimetic with broad somatotropin release inhibiting factor (SRIF) receptor binding and a unique antisecretory profile. Eur J Endocrinol. 2002; 146:707-716. [PubMed: 11980628]

68. Pasquali D, Rossi V, Conzo G, Pannone G, Bufo P, De Bellis A, Renzullo A, Bellastella G, Colao A, Vallone G, Bellastella A, Sinisi AA. Effects of somatostatin analog SOM230 on cell proliferation, apoptosis, and catecholamine levels in cultured pheochromocytoma cells. J Mol Endocrinol. 2008; 40:263-271. [PubMed: 18502819]

69. Scharf Y, Ben Arieh Y, Gellei B. Orbital metastases from extra-adrenal pheochromocytoma. Am J Ophthalmol. 1970; 69:638-640. [PubMed: 5437826] 
70. Philipps AF, McMurtry RJ, Taubman J. Malignant pheochromocytoma in childhood. Am J Dis Child. 1976; 130:1252-1255. [PubMed: 984010]

71. Hamilton BP, Cheikh IE, Rivera LE. Attempted treatment of inoperable pheochromocytoma with streptozocin. Arch Intern Med. 1977; 137:762-765. [PubMed: 141242]

72. Feldman JM. Treatment of metastatic pheochromocytoma with streptozocin. Arch Intern Med. 1983; 143:1799-1800. [PubMed: 6225404]

73. Herrera LO, Hossain ZM, Rafal HS, Frelick RW, Ashley PF, Lopez GE. Malignant pheochromocytoma (paraganglioma) of the organ of Zuckerkandl: a study of two cases. J Surg Oncol. 1980; 14:133-145. [PubMed: 6446627]

74. Bukowski RM, Vidt DG. Chemotherapy trials in malignant pheochromocytoma: report of two patients and review of the literature. J Surg Oncol. 1984; 27:89-92. [PubMed: 6237229]

75. Srimuninnimit V, Wampler GL. Case report of metastatic familial pheochromocytoma treated with cisplatin and 5-fluorouracil. Cancer Chemother Pharmacol. 1991; 28:217-219. [PubMed: 1855279]

76. Jirari A, Charpentier A, Popescu S, Boidin P, Eisenmann B. A malignant primary cardiac pheochromocytoma. Ann Thorac Surg. 1999; 68:565-566. [PubMed: 10475433]

77. Keiser HR, Goldstein DS, Wade JL, Douglas FL, Averbuch SD. Treatment of malignant pheochromocytoma with combination chemotherapy. Hypertension. 1985; 7:I18-I24. [PubMed: 3997232]

78. Edstrom EE, Hjelm Skog AL, Hoog A, Hamberger B. The management of benign and malignant pheochromocytoma and abdominal paraganglioma. Eur J Surg Oncol. 2003; 29:278-283. [PubMed: 12657240]

79. Naoi Y, Tamaki Y, Ooka M, Tsukamoto F, Miyoshi Y, Tanji Y, Taguchi T, Noguchi S. A case of metastatic pheochromocytoma with remarkable response to combination of cyclophosphamide, vincristine and dacarbazine. Gan To Kagaku Ryoho. 2003; 30:145-149. [PubMed: 12557721]

80. Wu D, Tischler AS, Lloyd RV, Delellis RA, de Krijger R, van Nederveen F, Nose V. Observer Variation in the Application of the Pheochromocytoma of the Adrenal Gland Scaled Score. Am J Surg Pathol. 2009; 33:599-608. [PubMed: 19145205]

81. Huang H, Abraham J, Hung E, Averbuch S, Merino M, Steinberg SM, Pacak K, Fojo T. Treatment of malignant pheochromocytoma/paraganglioma with cyclophosphamide, vincristine, and dacarbazine: recommendation from a 22-year follow-up of 18 patients. Cancer. 2008; 113:2020 2028. [PubMed: 18780317]

82. Kulke MH, Stuart K, Enzinger PC, Ryan DP, Clark JW, Muzikansky A, Vincitore M, Michelini A, Fuchs CS. Phase II study of temozolomide and thalidomide in patients with metastatic neuroendocrine tumors. J Clin Oncol. 2006; 24:401-406. [PubMed: 16421420]

83. Newlands ES, Stevens MF, Wedge SR, Wheelhouse RT, Brock C. Temozolomide: a review of its discovery, chemical properties, pre-clinical development and clinical trials. Cancer Treat Rev. 1997; 23:35-61. [PubMed: 9189180]

84. Ekeblad S, Sundin A, Janson ET, Welin S, Granberg D, Kindmark H, Dunder K, Kozlovacki G, Orlefors H, Sigurd M, Oberg K, Eriksson B, Skogseid B. Temozolomide as monotherapy is effective in treatment of advanced malignant neuroendocrine tumors. Clin Cancer Res. 2007; 13:2986-2991. [PubMed: 17505000]

85. Chrisoulidou A, Kaltsas G, Ilias I, Grossman AB. The diagnosis and management of malignant phaeochromocytoma and paraganglioma. Endocr Relat Cancer. 2007; 14:569-585. [PubMed: 17914089]

86. Patel PH, Chaganti RS, Motzer RJ. Targeted therapy for metastatic renal cell carcinoma. Br J Cancer. 2006; 94:614-619. [PubMed: 16465192]

87. Jimenez C, Cabanillas ME, Santarpia L, Jonasch E, Kyle KL, Lano EA, Matin SF, Nunez RF, Perrier ND, Phan A, Rich TA, Shah B, Williams MD, Waguespack SG. Use of the tyrosine kinase inhibitor sunitinib in a patient with von Hippel-Lindau disease: Targeting angiogenic factors in pheochromocytoma and other von Hippel-Lindau disease-related tumors. J Clin Endocrinol Metab. 2009; 94:386-391. [PubMed: 19017755] 
88. Joshua AM, Ezzat S, Asa SL, Evans A, Broom R, Freeman M, Knox JJ. Rationale and evidence for sunitinib in the treatment of malignant paraganglioma/pheochromocytoma. J Clin Endocrinol Metab. 2009; 94:5-9. [PubMed: 19001511]

89. Gross DJ, Munter G, Bitan M, Siegal T, Gabizon A, Weitzen R, Merimsky O, Ackerstein A, Salmon A, Sella A, Slavin S. The role of imatinib mesylate (Glivec) for treatment of patients with malignant endocrine tumors positive for c-kit or PDGF-R. Endocr Relat Cancer. 2006; 13:535540. [PubMed: 16728580]

90. Yao JC, Phan AT, Chang DZ, Wolff RA, Hess K, Gupta S, Jacobs C, Mares JE, Landgraf AN, Rashid A, Meric-Bernstam F. Efficacy of RAD001 (everolimus) and octreotide LAR in advanced low- to intermediategrade neuroendocrine tumors: results of a phase II study. J Clin Oncol. 2008; 26:4311-4318. [PubMed: 18779618]

91. Sausville EA, Tomaszewski JE, Ivy P. Clinical development of 17-allylamino, 17demethoxygeldanamycin. Curr Cancer Drug Targets. 2003; 3:377-383. [PubMed: 14529389]

92. Averbuch SD, Steakley CS, Young RC, Gelmann EP, Goldstein DS, Stull R, Keiser HR. Malignant pheochromocytoma: effective treatment with a combination of cyclophosphamide, vincristine, and dacarbazine. Ann Intern Med. 1988; 109:267-273. [PubMed: 3395037] 
Treatment Algorithm

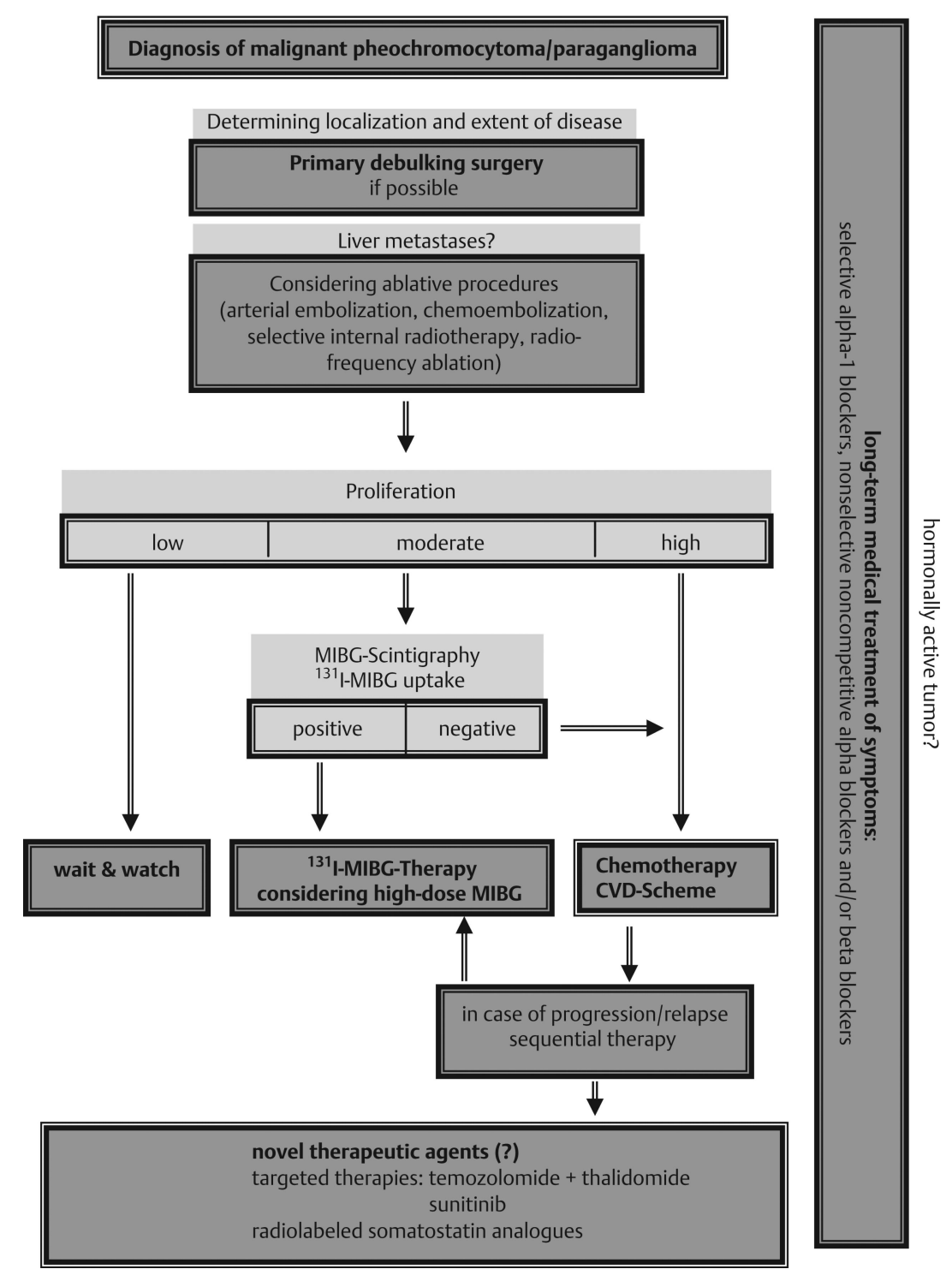

Fig. 1.

Suggested treatment algorithm of malignant pheochromocytoma. 


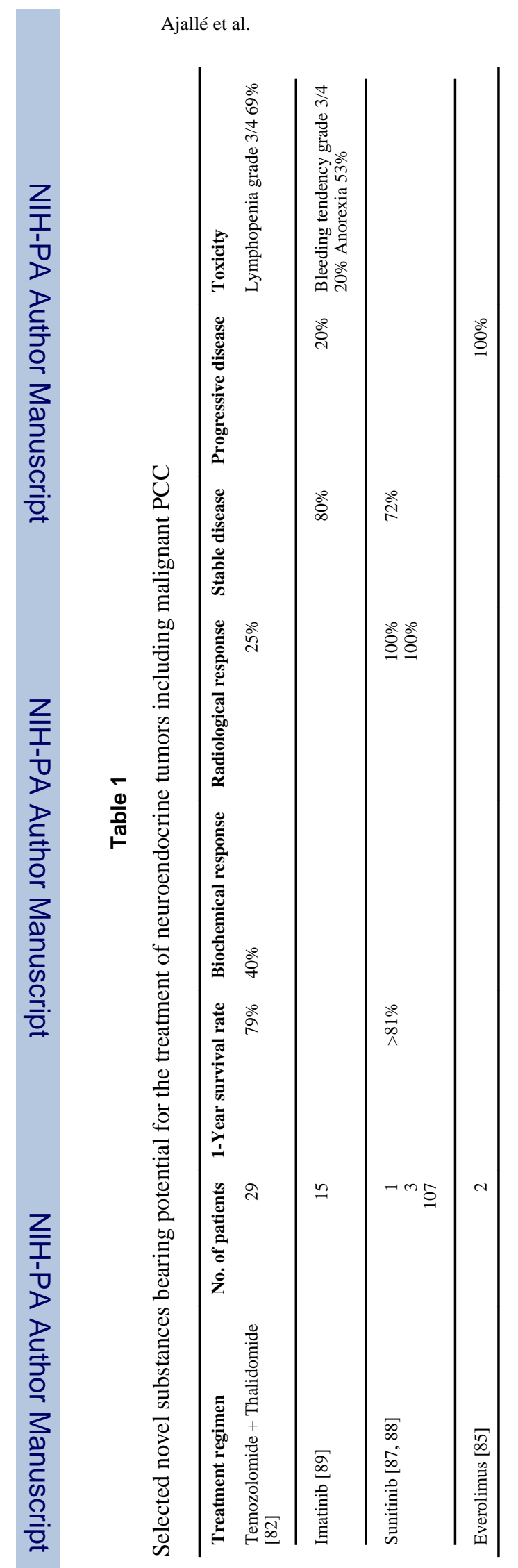

Horm Metab Res. Author manuscript; available in PMC 2013 May 20. 